\title{
Cyclostratigraphy and orbital forcing of the Chang 7 lacustrine shales during the Middle Triassic greenhouse period
}

\author{
ZHIJUN JiN ${ }^{1,2, *}$, RUI ZHANG ${ }^{1,2, *}$, QUANYOU LIU ${ }^{1,2}$, \\ PENG LI I,2 \\ ${ }^{1}$ State Key Laboratory of Shale Oil and Gas Enrichment \\ Mechanisms and Effective Development, SINOPEC, \\ Beijing 100083, China (*correspondence: \\ jinzj.syky@sinopec.com; 1139365064@qq.com) \\ ${ }^{2}$ Petroleum Exploration and Production Research Institute, \\ SINOPEC, Beijing 100083, China
}

The Middle Triassic was a key period that witnessed the evolution of Earth system processes and the commencement of a terrestrial lake in the Ordos Basin, Central China. A high-precision stratigraphic framework is the key to understanding the nature and pattern of tectonic and astronomical processes. Time series analyses of magnetic susceptibility (MS) data were performed on the deep lacustrine shale-dominated Chang 7 Member of the Yanchang Formation. Our results reveal cyclic variations with wavelengths of $5.37 \mathrm{~m}, 1.39-1.78 \mathrm{~m}, 0.48 \mathrm{~m}$, and $0.24-0.30$ $\mathrm{m}$, which are driven by long-eccentricity, short-eccentricity, obliquity, and precession in the Middle Triassic. The 405-kyr tuned floating astrochronological time scale (FATS) shows that the depositional duration of the Chang 7 is approximately 5 Myr. Along with U-Pb age constraints, our FATS further confirms that the Chang 7 shales mainly developed in the Ladinian Stage, and that the upper part of the Chang 7 spanned the Middle/Late Triassic boundary.

During the Middle Triassic greenhouse period, the Ordos Basin would response to humid subtropical climate variation via the intertropical convergence zone (ITCZ) dynamics. Eccentricity amplitude modulation of precessiondriven ITCZ oscillations could have accelerated weathering and nutrient supply in the Tethys realm. The Ladinian Chang7 shales were closely associated with major humid events from the Tethyan subtropics. The humid events could have amplified the monsoon activities and ultimately resulted in the occurrence of black shales in the Ordos Basin. The age and duration of the Chang 7 deposition suggest a temporal and genetic linkage between the responses of the Chang 7 shales in the Ordos Basin and the Indosinian Orogeny in the Qinling orogenic belt. We propose that the evolution of the regional geodynamic system between the Ordos Basin and the Qinling orogenic belt amplified the orbitally paced paleoenvironmental changes. 